\title{
EXPLORING THE “EGG/PLANT QUESTION”: WHAT BEST EXPLAINS THE PATTERNS OF AMNIOTE DIVERSIFICATION?
}

REISZ*, Robert R., Dept. of Biology, Erindale Campus, University of Toronto, Mississauga, Ontario, L5L 1C6, CANADA; MOORE, Brian R., Dept. of Biology, Erindale Campus, University of Toronto, Mississauga, Ontario, L5L 1C6, CANADA.

A rich fossil record documents 315 my of amniote evolution. The available evidence indicates that amniotes rapidly became the most conspicuous members of terrestrial ecosystems, and have exhibited a remarkable history of ecological and biological diversification. The "evolutionary success" of this group has traditionally been attributed to the origin of the cleidoic egg, interpreted to be the "key innovation" which presumably allowed them to invade and exploit more effectively fully-terrestrial environments. This hypothesis has become uncritically accepted as a central paradigm of amniote evolutionary studies. It predicts that the origin of the cleidoic egg should be coupled temporally with accelerated rates of diversification in this group. Our analysis of the patterns of amniote diversification (i.e., fossil-species diversity) falsifies the "cleidoic egg" hypothesis: although amniotes first appear in the Early Pennsylvanian (Westphalian A), the rate of taxonomic diversification does not change substantially until the Permo-Carboniferous boundary, revealing that these two evolutionary events are separated by at least $30 \mathrm{my}$. We propose an alternative hypothesis: terrestrial herbivory (defined here as the consumption of cellulose-rich leaves, roots and shoots) is the key innovation responsible for the accelerated taxonomic diversification of amniotes. Among vertebrates, terrestrial herbivory is a feeding strategy exclusive to amniotes. This alternative hypothesis is consistent with the patterns of amniote diversification chronicled by the fossil record: the first evidence of terrestrial amniote herbivores coincides with the accelerated rates of diversification in amniotes.

These two hypotheses may not be mutually-exclusive explanations for the evolutionary success of amniotes. It is possible that both attributes may be acting as a "key-chain" of innovations. The maintenance of terrestrial herbivory in modern amniotes is universally reliant upon the intergenerational transfer of cellulolytic microbes, which, in turn, requires direct terrestrial development, made possible by the evolution of the cleidoic egg. 